\title{
Advanced Manufacturing and Instrumentation for Neutron Chopper Design
}

\author{
James Lư ${ }^{1 *}$, Dr. Piyush Sabharwall², Dr. Brenden Heidrich², and Prof. Rich Christensen ${ }^{3}$
}

Neutron choppers are devices that pulsate and filter beams of neutrons at varying energy levels using rotating chopper blades. Advancements in this technology over the past 80 years have played a crucial role for a variety of applications and discoveries, such as obtaining nuclear cross-section data. Over the last decade, computational scattering science has helped shed light on issues with stress reduction and thermal control of neutron choppers by linking computer simulations with physics experiments. Advanced manufacturing and instrumentation, an emerging technology that makes physical products efficient and sustainable beyond virtual study, may enable breakthroughs in neutron chopper design. This survey investigates a modern method to design stable rotors and provide effective cooling for neutron choppers. By consulting experts on neutron choppers and thermodynamic technologies, the review identifies the two key themes of coolant optimization and rotor fabrication. An extensive literature search follows to evaluate the effectiveness of the state-of-the-art solutions with feedback from the multidisciplinary experts. For example, the U.S. Department of Energy identifies the opportunities to fabricate ${ }^{157} \mathrm{Gd}$ components with advanced manufacturing technologies. Specifically, additive manufacturing (3D printing) is used to fabricate components with unprecedented structural complexity that facilitate the energy filter effect. Computational results show that methyl formate is a better coolant than other fluids. The study leads to a proof-of-concept that advanced manufacturing and instrumentation improve heat dissipation and component fabrication.

\section{INTRODUCTION}

Neutron choppers, devices that generate uniform-energy neutron beam pulses using velocity selection and phase control, are in high demand for the study of energy and matter. They hold a multitude of applications in diverse fields. For example, studies have used neutron optics to delve into properties of magnetism, analyze protein structures, and examine stress and strain in jet engines (Soldner 2015). As explosive materials emit characteristic gamma rays, applying controlled neutron beams can detect improvised explosive devices (Pesente et al. 2006). Other studies have used a Fermi neutron chopper to obtain unknown cobalt cross-section measurements. Measuring cross-sections enables the calculation of nuclear reaction rates, which is critical in the optimization of nuclear energy generation (Mobley 1966).

Address correspondance to:

'Brown University, Providence, RI 02912

${ }^{2}$ Idaho National Laboratory, Idaho Falls, ID 83415

${ }^{3}$ University of Idaho, Idaho Falls, ID 83402

*james_lu@brown.edu

doi:10.22186/jyi.38.6.60-67



Except where otherwise

Acceptance date: November 2019

Publication date: December 2020
This review focuses on neutron choppers that deploy highspeed rotation (up to $500 \mathrm{~Hz}$ ) and generate substantial heat and stress. After over 80 years of research and development, this instrumentation has reached a state of optimization, and engineers expect new research channels to overcome the historical limitations of only making incremental improvements (Crawford 2000). This study explores advanced manufacturing for neutron chopper design. Advanced manufacturing is to improve products and processes with the rapid transfer of modern techniques enabled by Information Communication Technology (PCAST 2010). The work aims to select neutron-absorbing material and designing chopperblade structure with phase changing fluid to effectively filter neutron beams and reduce heat generated by chopper rotation.

The remainder of this review highlights methods used for this survey, evaluates selected studies in four categories, and discusses conclusions. The first category of the selected studies on neutron chopper development shows a trend in modern design methods with computing. The second traces the origin of advanced manufacturing as an emerging technology to improve neutron chopper design. The third and fourth categories focus on the two key themes: effective cooling and stable structuring, respectively. Overall, this work provides energy researchers with a new means for generating pulsed uniform-energy neutron beams. It also attracts an undergraduate audience in diverse disciplines to pursue nuclear engineering.

\section{METHODS}

Literature reviews examine scholarly works on a topic using different methods. Meta-analysis, popular among health sci- 




Figure 1. Common Chopper Designs (Sutton 2018). A) Fermi Chopper. B) Disk Chopper.

entists, applies statistical techniques to integrate the results of studies included in a review (Cochrane 2020). Nuclear engineers often use thematic analysis to synthesize stateof-the-art solutions on a well-defined problem. They consult domain experts to identify key themes and evaluate published works (including government/industry documents) in order to draw conclusions within specified categories. This qualitative method proves the concept with modeling formulas, rather than statistical datasets, to conduct exploratory research.

For pedagogical simplicity targeted to an undergraduate audience, we choose a 1966 neutron chopper rotor for proof-of-concept calculations in the later discussion on coolant optimization (Harling 1966). In the discussion on rotor manufacturing, a recent $3 \mathrm{D}$ printing example explores the opportunities to fabricate $157 \mathrm{Gd}$ components with four of the clean energy advanced manufacturing technologies: additive manufacturing (i.e., 3D printing); advanced sensors, controls, platforms and modeling for manufacturing (ASCPMM); materials for harsh service conditions; process intensification (Sher 2019). The U.S. Department of Energy (DOE) has identified fourteen advanced manufacturing technologies for clean energy. By examining the applicability and effectiveness of each to revolutionize neuron chopper design, our study discovers a potential solution that utilizes these four out of the DOE's fourteen advanced manufacturing technologies to improve heat dissipation and handle structural complexity.

To determine the viability for system data collection by ASCPMM, we also conduct a quick market search on sensors by analyzing products.

In keeping with the exploratory nature of this research, we use modeling formulas rather than statistical datasets to conduct studies qualitatively.

For coolant optimization, Equation 1 calculates the temperature difference, where $\Delta Q$ is the heat change in joules, $m$ is the mass, $c$ is the heat capacity, and $\Delta T$ is the temperature difference in degree Celsius (Harling 1966).

$$
\Delta Q=m \cdot c \cdot \Delta T
$$

For rotor construction, a set of four equations model the phenomenon (Mobley 1966). The heating rate ([Q]) from absorption can be calculated from the probability of interaction per unit of surface area $\left(\sum_{a}^{x}\right)$. Equation 2 calculates interac- tion probability, where $\sigma_{a}^{x}$ is microscopic cross-section and $N^{x}$ is atomic density. As shown in Equation 3, the heating rate is the product of current system heat $\langle Q\rangle$, interaction probability, and neutron flux $(\varphi)$.

$$
\begin{gathered}
\sum_{a}^{x}=\sigma_{a}^{x} \cdot N^{x} \\
{[Q]=<Q>\cdot \sum_{a}^{x} \cdot \varphi}
\end{gathered}
$$

Equation 4 models the relation between wavelength distribution and rotational velocity of neutron choppers, wherein $V_{m}$ is the minimum neutron velocity, $\omega$ is the rotational velocity (radian per second), $R$ is the rotation radius, and $S$ is the spacing between blades. Equation 5 calculates neutron burst width $(T)$.

$$
\begin{aligned}
V_{m} & =\frac{\omega R^{2}}{s} \\
T & =\frac{s}{\omega R}
\end{aligned}
$$

\section{NEUTRON CHOPPERS}

This multidisciplinary survey starts with a literature review of neutron chopper development over the last 80 years. It then comments on recent studies about the applicability of advanced manufacturing in neutron choppers. The survey proceeds with our exploratory research to improve neutron chopper design using advanced manufacturing and instrumentation, focused on coolant optimization and rotor manufacturing.

\section{History and Operation}

Three years after the discovery of the neutron in 1932, two pairs of duralumin disks proved the concept of neutron choppers at Columbia University (Dunning et al. 1935; Copley and Udovic 1993). People would eventually link the discovery of the neutron with the development of the atomic bomb in the Manhattan Project during World War II. Enrico Fermi, lead scientist for the Manhattan Project and 1938 laureate of Nobel Prize in Physics, hoped that "the building of power plants, production of radioactive elements for science and medicine would become the paramount objectives." (Fermi 1952). In 1947 at Argonne National Laboratory, he built a chopper that bears his name to this day (Fermi et al. 1947). Starting from the Fermi chopper, milestones in neuron chopper design included phased neutron scattering in the 1960s (Egelstaff 1965), pulsed neutron scattering in the '80s (Windsor 1981), and computational scattering science in the '90s (Fultz et al. 2010). After decades of exploration and evolution, neutron chopper technology reached its maturity in 2015 (Sutton 2018).

Basic neutron choppers house neutron-absorbing disks rotating at high speeds to "chop" neutron beams, thus producing neutron beams of a specific energy distribution. Choppers involve a two-step process: first divide a beam of neutrons from a source into pulses and then filter neutrons of a certain velocity from these beams. The end goal is to pulse a controlled beam of neutrons with uniform energy.

In the first step, common choppers, resembling the Fermi and disk chopper designs shown in Figure 1, divide the 

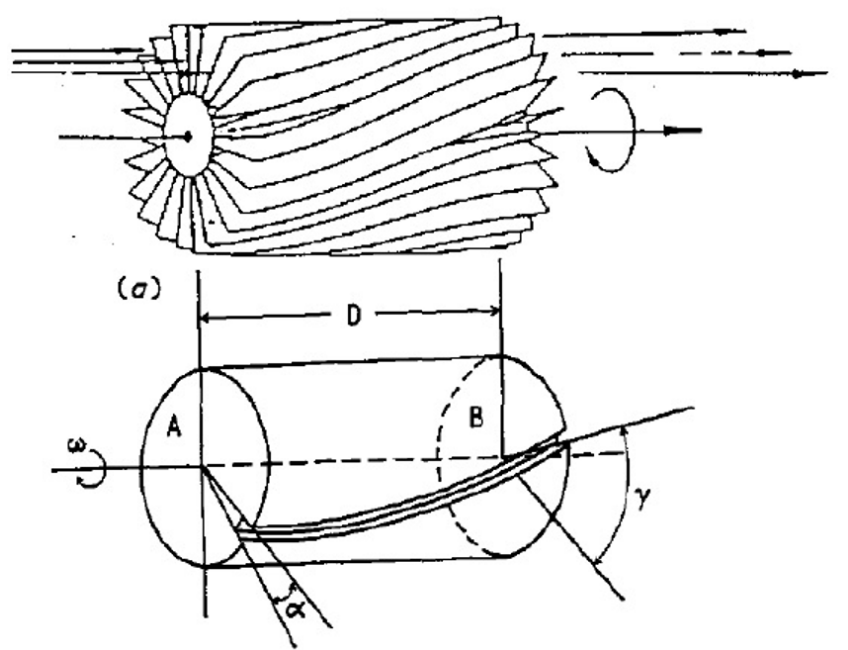

Figure 2. Rotor of a Velocity Selector (Soldner 2015).

beam of neutrons into pulses. Pulsed beams carry a variety of useful data including wavelength information, as well as time and spatial localization of the pulse (Soldner 2015). The resulting neutron beam spans a large velocity range.

In the second step, the neutron beam undergoes velocity selection (the rejection of neutrons in the beam outside a desired velocity range) using methods similar to filtering. One means of velocity selection is the "time of flight" method, which employs an electronic counter to measure the number of neutrons detected within a velocity range (Mobley 1966; Copley and Udovic 1993). Other ways of selecting velocity are mechanical monochromatization or crystal diffraction. Mechanical velocity selectors shown in Figure 2 rotate neutron-absorbing blades at varying speeds to remove certain energies from a beam as it passes through. Crystal diffraction utilizes crystals to isolate certain energy neutrons (Lowde 1960). This review focuses on mechanical velocity selectors.

Neutron chopper technology faces problems concerning heat dissipation and structural instability. The introduction of additional components rotating at very high speeds results in a substantial amount of heat generated in the rotor mechanism. High-speed rotation also increases the risk of structural failure. These complications posit the challenges in implementing rotor-cooling methods and constructing stable and complex chopper blades. Innovative instrumentation ideas meet some of these challenges by enhancing sample environment capabilities and speeding parametric studies (Crawford 2000). For example, the Cold Neutron Chopper Spectrometer at the Spallation Neutron Source in Oak Ridge National Laboratory has facilitated user experiments with leading-edge performance since 2009 (Ehlers et al. 2016). Furthermore, computational scattering science is expected to enhance chopper design while increasing our understanding of energy and matter in the context of neutron choppers (Fultz et al. 2018).

\section{Promises of Advanced Manufacturing}

According to the Subcommittee for Advanced Manufacturing

of the National Science and Technology Council,

Advanced manufacturing is a family of activities that (a) depend on the use and coordination of information, automation, computation, software, sensing, and networking, and/or (b) make use of cutting edge materials and emerging capabilities enabled by the physical and biological sciences, for example nanotechnology, chemistry, and biology. It involves both new ways to manufacture existing products, and the manufacture of new products emerging from new advanced technologies.

(SAM 2016)

The term "advanced manufacturing" bears a variety of definitions from whether modern characteristics are present in an industry to what/how products are made. The confusion contributed to underinvestment in U.S. manufacturing (Panchak 2012). To define the field where America retains its leadership position, the U.S. President's Council of Advisors on Science and Technology (PCAST) dug the question "What Is Advanced Manufacturing?" by discussions with leading experts and a review of the literature (PCAST 2010). With coordinated action by industry, academia, and government, PCAST eventually offered a comprehensive definition of advanced manufacturing as a starting point (PCAST 2012). Specifically, the U.S. Department of Energy (DOE) explored the concept of advanced manufacturing for energy technologies, reporting,

Smart manufacturing is an emerging field that combines physical systems with big data and intelligence. It is also referred to as Advanced Manufacturing, Digital Manufacturing ... essentially it is about smartly extracting information from the system to improve overall efficiency of manufacturing.

(Rachuri 2017)

This review utilizes four of the fourteen DOE-identified advanced manufacturing technologies for clean energy (DOE 2015a), readily applicable to nuclear energy:

1. Additive Manufacturing (DOE 2015b): This technology consists of fabrication techniques involving layered filaments. Nuclear technologies with complex structures can be efficiently constructed while possessing special material properties such as durability and high thermal conductivity.

2. Advanced Sensors, Controls, Platforms and Modeling for Manufacturing (ASCPMM) (DOE 2015c): This technology, based on Information Communication Technology (ICT), aims at collecting system data, automating operation, and optimizing manufacture with simulations. Advanced sensors could monitor properties such as rotational velocity and absorption in neutron choppers. Furthermore, data collected for rotational systems could improve the implementation of system simulations.

3. Materials for Harsh Service Conditions (DOE 2015d): These materials can withstand conditions such as high temperatures, mechanical wear, and neutron irradiation. 


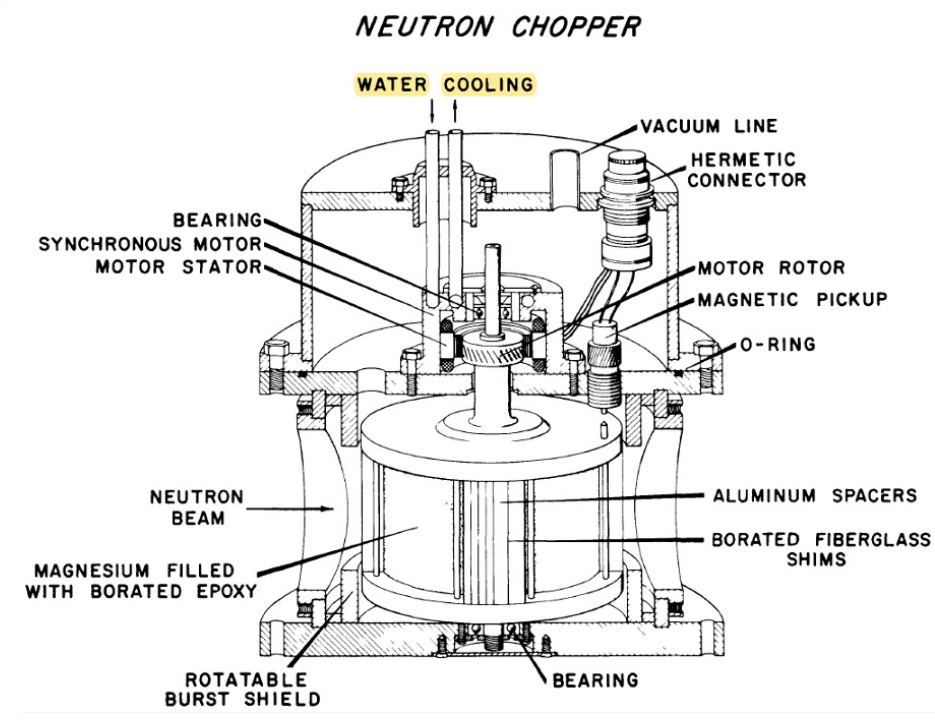

Figure 3. Neutron Chopper with Water Cooling (Harling 1966).

Reliable neuron choppers depend on appropriate neutron-absorbing material and stable structure.

4. Process Intensification (DOE 2015e): This refers to merging the conduction of technical processes into one instrument for cost-effective manufacturing. A neutron chopper carries out both beam pulsing and filtering processes in a single piece of equipment, saving costs.

These four technologies collectively determine an effective manufacturing method for cooling and constructing rotor blades with utilizing conventional fixes and facilitating the use of computational scattering science in studies on neutron choppers. The coolant research compares coolant fluids based on four parameters and identifies methyl formate as the best choice. A case study on 3D printed heat exchangers motivates the use of additive manufacturing under process intensification and ASCPMM with materials for harsh service condition to create improved neutron absorbing rotor blades from ${ }^{157} \mathrm{Gd}$-covered aluminum.

\section{Coolant Optimization}

Today's neutron chopper systems typically employ water cooling for motor components but not the rotor itself. In Figure 3 , the chopper features a water-cooling piping system around the motor compartment. However, heat generated by the rotor must be dissipated through the bearings via conduction. This chopper encases the rotors in a helium environment for better cooling at the cost of negligible drag (Harling 1966).

The system depicted in Figure 3 requires about 100 watts to power two 341-HP motors at 20 ounces-inches of torque, resulting in an angular speed of 6,000 revolutions per minute (Harling 1966). Note that the motor was functioning at 50 percent efficiency, implying the loss of at least 50 watts. Assuming all wasted energy is thermal energy, a single motor releases more than 25 joules of energy every second to the environment.
Table 1. Coolant Fluid Comparison. Data for phase change temperature from (Engineering ToolBox 2005), for heat capacity from (NIST Standard Reference Database Number 69 2018), for thermal conductivity from (Yaws 1995; NOAA 1999; Engineering ToolBox 2008; Engineers Edge 2019), and for cost from (CAS DataBase List 2016; Right Price Chemicals n.d.).

\begin{tabular}{|lccccc|}
\hline Name & $\begin{array}{c}\text { Phase Change } \\
\mathrm{kPa} \\
\left({ }^{\circ} \mathrm{K},{ }^{\circ} \mathrm{C}\right)\end{array}$ & $\begin{array}{c}\text { Heat Ca- } \\
\text { pacity at } \\
47.2^{\circ} \mathrm{C} \\
(\mathrm{J} / \mathrm{mol} \times \mathrm{K})\end{array}$ & $\begin{array}{c}\text { Thermal } \\
\text { Conductivity } \\
(\mathrm{W} / \mathrm{m} \mathrm{K})\end{array}$ & $\begin{array}{c}\text { Cost for } \\
1 \mathrm{~L} \\
(\mathrm{USD})\end{array}$ \\
\hline $\begin{array}{l}\text { Water } \\
\begin{array}{l}\text { Methylene } \\
\text { Chloride }\end{array}\end{array}$ & 313.7 & 100.0 & 75.94 & 0.609 & 1.00 \\
$\begin{array}{l}\text { Trichlo- } \\
\text { rotrifluo- } \\
\text { roethane }\end{array}$ & 320.8 & 47.8 & 172.5 & 0.075 & $\begin{array}{l}\text { discon- } \\
\text { tinued }\end{array}$ \\
$\begin{array}{l}\text { Methyl } \\
\text { formate }\end{array}$ & 304.7 & 31.7 & 130.0 & 0.18 & 201.00 \\
\hline
\end{tabular}

To calculate the temperature difference, we idealize a motor as a steel cylinder with a heat capacity of 0.490 joules per gram per degree Celsius. We approximate the motor mass using the known mass of other motors whose diameter is approximately $45 / 16$ inches. Assuming the motor is a cylinder of uniform diameter and 4 inches tall, we estimate its volume as $823.7 \mathrm{~cm}^{3}$. Given that the density of the motor is the same as the density of steel $\left(\sim 7.9\right.$ grams per $\left.\mathrm{cm}^{3}\right)$, we estimate its mass as 6507.2 grams. Referring to Equation 1 in the Methods section, the temperature of a neutron chopper motor would increase by approximately $0.45^{\circ} \mathrm{C}$ every minute. A study measuring cobalt cross sections ran the device for one hour to obtain a data set (Mobley 1966). Assuming that the environment is at an ambient temperature of $20^{\circ} \mathrm{C}$, we estimate the motor's temperature to rise to $47.2^{\circ} \mathrm{C}$ within that operating time.

The most efficient coolant would transfer heat at the same rate at which the rotor heats. It is also desirable for the fluid to have high heat capacity, high thermal conductivity, and an acceptable phase change temperature. We identify four potential coolants and compare the four major parameters of their thermodynamic properties in Table 1. Although phase change has the advantage of keeping the coolant's temperature stable, a low-boiling-point liquid could cause a catastrophic system failure because of the liquid's flammability. Other design alternatives such as heat exchangers and ventilating fans that raise the flow rate of the common water coolant should also be considered.

\section{Rotor Manufacturing}

A case study demonstrates the application potential for 3D printing with ASCPMM, process intensification and materials for harsh service conditions in rotor fabrication (DOE 2015b; DOE 2015c; DOE 2015d; DOE 2015e). Recently, General 


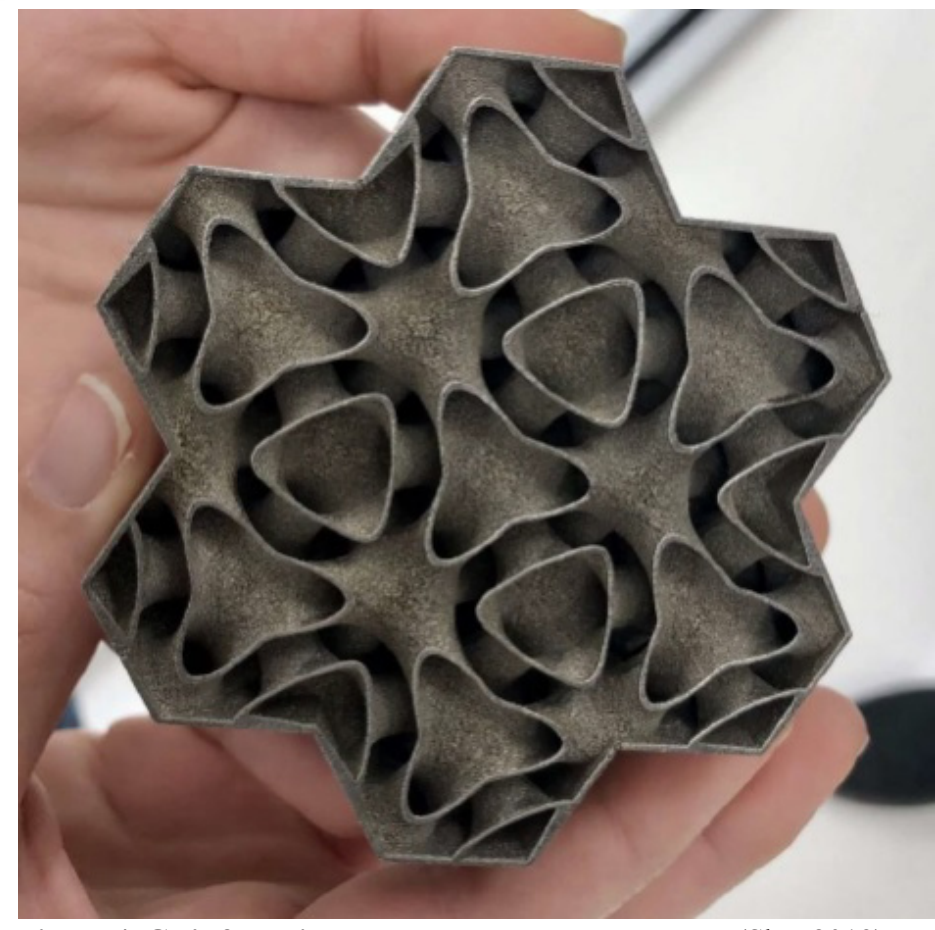

Figure 4. GE's 3D Printed Heat Exchanger Prototype (Sher 2019).

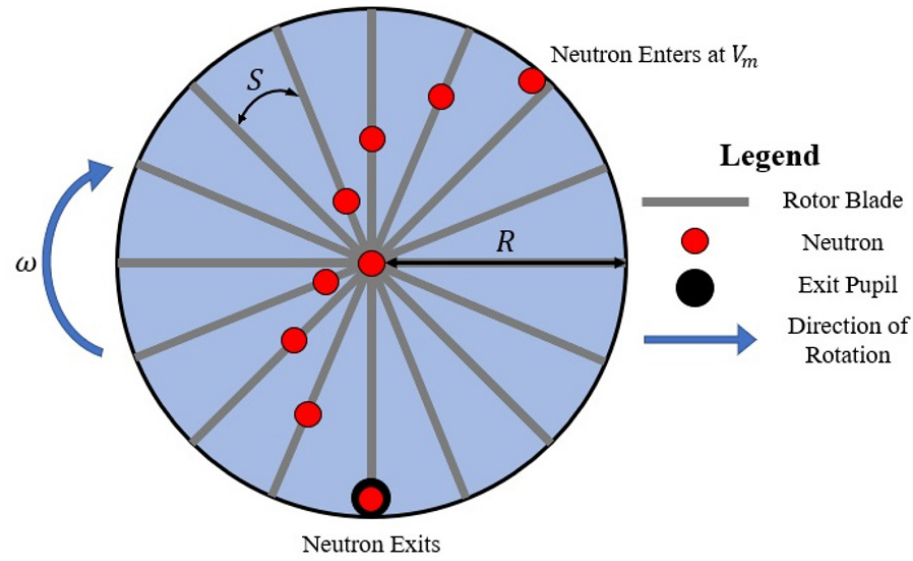

Figure 5. Neutron Trajectory through Chopper Blades.

Electric's Research \& Development division documented the use of 3D printing to fabricate a heat exchanger, a device that transports thermal energy without moving parts. This technology could be employed in nuclear systems such as the secondary loop of a pressurized water reactor. As shown in Figure 4, this heat exchanger features a complex structure of trifurcating network, mimicking human lungs that is only attainable through additive manufacturing. The printing filament uses a heat-resistant nickel superalloy. The General Electric's product is anticipated to outperform current heat exchanger technologies significantly (Sher 2019).

General Electric's 3D-printed heat exchanger highlights additive manufacturing's potential to create devices far more endurable and complex than traditional mold-and-cast methods. Consequentially, additive manufacturing is a favorable
Table 2. Absorption Material Comparison. Data for absorption cross-section from (Glossary n.d.), and for equations from (Lee et al. 2014; Glossary n.d.).

\begin{tabular}{|c|c|c|c|}
\hline Name & $\begin{array}{c}\text { Absorption } \\
\text { Cross- } \\
\text { Section for } \\
0.025 \mathrm{eV} \\
\text { Neutron } \\
\text { (barns) }\end{array}$ & $\begin{array}{c}\text { Thickness } \\
\text { of isotopic } \\
\text { material } \\
\text { that will } \\
\text { reduce } \\
\text { beam by } \\
99 \%(\mu \mathrm{m})\end{array}$ & $\begin{array}{c}\text { Thermal Neutron Absorption } \\
\text { Equation }\end{array}$ \\
\hline${ }^{113} \mathrm{Cd}$ & 20,000 & 50 & $\begin{array}{l}n_{\text {th }}(0.025 \mathrm{eV})+{ }_{48}^{113} \mathrm{Cd} \rightarrow{ }_{48}^{114} \mathrm{Cd}^{*} \\
\rightarrow{ }_{48}^{114} \mathrm{Cd}+\gamma\end{array}$ \\
\hline${ }^{10} \mathrm{~B}$ & 3,840 & 94 & $\begin{array}{l}{ }^{10} \mathrm{~B}+n_{\text {th }}(0.025 \mathrm{eV}) \rightarrow{ }^{4} \mathrm{He}^{2+}+{ }^{7} \mathrm{Li}^{3+} \\
+2.79 \mathrm{MeV}(6 \%) \\
{ }^{10} \mathrm{~B}+n_{\text {th }}(0.025 \mathrm{eV}) \rightarrow{ }^{4} \mathrm{He}^{2+}+{ }^{7} \mathrm{Li}^{3+} \\
+2.31 \mathrm{MeV}+\gamma(0.48 \mathrm{MeV})(94 \%)\end{array}$ \\
\hline${ }^{157} \mathrm{Gd}$ & 254,000 & 6 & $\begin{array}{l}{ }^{157} \mathrm{Gd}+n_{t h} \rightarrow{ }^{156} \mathrm{Gd}+\gamma(7.88 \\
\mathrm{MeV})+\mathrm{ACK}-\text { electrons }(4.2 \\
\mathrm{keV})\end{array}$ \\
\hline
\end{tabular}

candidate for the fabrication of neutron chopper rotors. Harsh service environments, especially those affected by nuclear radiation, are a major factor in material development.

Chopper rotors commonly use neutron-absorbing materials with elements such as cadmium, boron, and gadolinium for their ability to absorb without undergoing fission. We also identify three isotopes commonly used to absorb thermal neutrons and compare their atomic properties along with their thermal neutron absorption equations, as shown in Table 2. Based on Equations 2 and 3 in the Methods section, greater microscopic cross-section, $\sigma_{a}^{x}$, leads to increased heating rate, $[Q]$.

Mirrortron Fermi choppers feature aluminum blades coated with boron or gadolinium. Additive manufacturing, with its accompanied methods, opens the door to fabricating rotors of previously unattainable geometries, thus further improving the filtering of neutron beam energy distribution. Recently, there have been several projects conducted using additive manufacturing to generate complex structures from boron carbides. For example, one study involves gelcasting high density $B_{4} C / C$ into 3D-printed molds (Lu et al. 2018).

Neutron chopper blades need to retain their curved geometry to absorb thermal neutrons of a specific velocity. As a moving neutron's energy is purely kinetic, neutrons of the same velocity have the same energy. Moreover, neutrons of differing mass and speed have differing trajectories. The neutron chopper blades act as a filter by rotating at a certain speed to allow only neutrons possessing a specific energy to fly between them, as shown in Figure 5 . Other neutrons do not follow this path and are absorbed by the blades. The desired wavelength distribution relates to the rotational velocity of a neutron chopper as modeled by Equation 4 in the Methods section. 
Table 3. Sensor Samples from Market Search.

As illustrated in Figure 6, the chopping removes variance and tightens the neutron energy distribution. Faster chopping and more choppers improve resolution for applications such as obtaining cross-section data. However, neutron burst width $(T)$ decreases with faster rotation, as shown in Equation 5, resulting in a trade-off between beam resolution and low-energy attenuation.

\section{DISCUSSION}

Our studies of alternative cooling and neutron absorption methods with data are reported in Tables 1 and 2. Due to its phase change temperature, high heat capacity, and high thermal conductivity, methyl formate is the most effective coolant for neutron chopper rotors. The phase change at $31.7^{\circ} \mathrm{C}$ allows the fluid to absorb thermal energy without temperature change. Despite the phase change temperature being under $47.2^{\circ} \mathrm{C}$ estimated in the Coolant Optimization subsection, the fluid's high heat capacity and high thermal conductivity outweigh its low phase change temperature and permit the fastest energy transfer.

Based on material data and current technology, $157 \mathrm{Gd}$ is effective due to its nontoxicity and high absorption crosssection for $0.025 \mathrm{eV}$ neutrons (254,000 barns). In addition, heat generation from neutron absorption would be negligible. The chopper blades could be fabricated from light aluminum and coated with $157 \mathrm{Gd}$. According to Table 2, 157 $\mathrm{Gd}$ needs the thinnest coating of isotopic material to absorb neutrons effectively. The result has negligible effect on chopper weight while mitigates cost.

ASCPMM involves closed-loop autonomous operation with sensors to analyze performance, controllers to adjust operation, and platform/modeling to make decisions. Conducting a market search revealed that there currently exist several sensors to measure quantities such as torque, angular position, and temperature for system data collection of ASCPMM, as listed in Table 3. Measurements can be applied to prompt a system response. Data from sensors coupled with carefully tuned control systems can provide results far more accurate than current systems. Other sensors output data into readily manipulatable code to simulate various scenarios for decision making or performance tradeoff. From the perspective of instrumentation, ideal sensors are specialized for a low temperature and pressure range $\left(98.5^{\circ} \mathrm{C}\right.$ and $101.35 \mathrm{kPa}$, respectively) and can perform at high rotations (up to $500 \mathrm{~Hz}$ ).

This study involved an extensive literature search that synthesized the work of several multidisciplinary experts on neutron chopper design in order to attain effective heat dissipation and sustainable structure construction. The review explores a potential solution using advanced manufacturing to meet various challenges in the design and manufacture of neutron chopper rotors. Four of the fourteen advanced

\begin{tabular}{|c|c|c|}
\hline Sensor & Manufacturer & Functionality \\
\hline T40HS & $\begin{array}{l}\text { HBM } \\
\text { http://www.hbm. } \\
\text { com/en/5673/t40hs- } \\
\text { high-speed-torque- } \\
\text { transducer/ }\end{array}$ & $\begin{array}{l}\text { Torque } \\
(>45,000 \mathrm{rpm})\end{array}$ \\
\hline STCS50 R5K & $\begin{array}{l}\text { P3 America } \\
\underline{\text { http://p3america.com// }} \\
\underline{\text { angle-sensors/ }}\end{array}$ & $\begin{array}{l}\text { Angle position } \\
\text { (linearity tolerance: } \pm 0.1 \% \text { ) }\end{array}$ \\
\hline $\begin{array}{l}\text { TSD25 series } \\
\text { temperature } \\
\text { switch }\end{array}$ & $\begin{array}{l}\text { ProSense } \\
\text { http://www.automa- } \\
\text { tiondirect.com/Temp- } \\
\underline{\text { Sensors }}\end{array}$ & $\begin{array}{l}\text { Temperature } \\
\text { (range: }-20 \text { to } 140{ }^{\circ} \mathrm{C} \text { ) }\end{array}$ \\
\hline
\end{tabular}

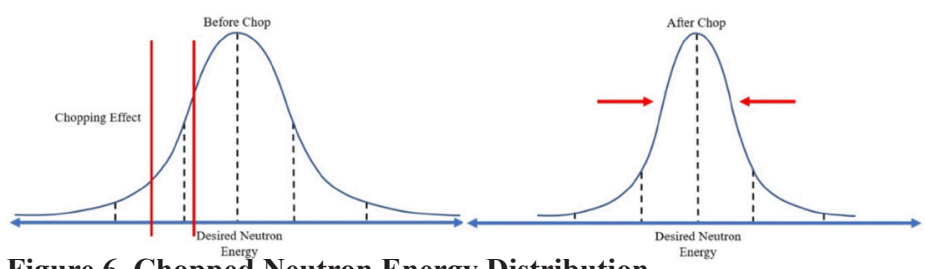

Figure 6. Chopped Neutron Energy Distribution.

manufacturing technologies defined by DOE for clean energy, applicable for nuclear energy, can be implemented to improve cooling methods and handle the structural complexity of neutron choppers.

The four technologies, namely additive manufacturing, ASCPMM, materials for harsh service condition, and process intensification, collectively determine an effective manufacturing method for cooling and constructing rotor blades. They utilize conventional fixes in the 80-year making for neutron choppers and facilitate the emerging field of computational scattering science for studies on neutron choppers. The coolant optimization research focuses on four parameters and reveals methyl formate as the best choice compared to other coolant fluids. A case study on 3D-printed heat exchangers motivates the usage of additive manufacturing under process intensification and ASCPMM with materials for harsh service condition to create improved neutron-absorbing rotor blades from ${ }^{157} \mathrm{Gd}$-covered aluminum.

This research offers an advanced method for obtaining pulsed uniform-energy neutron sources for a variety of applications. As stated earlier, nuclear cross-section data can be further discovered, potentially providing more efficient nuclear reactions to generate increased energy output to meet national demand. The topic attracts an undergraduate audience in diverse disciplines to pursue nuclear engineering in relation to the development of clean energy to combat climate change, radioactive materials in the fight against cancer, and other applications. Future work will explore methods for system optimization, specifically pipe systems and rotor geometry, which will include the construction and testing of a prototype based off this review 


\section{ACKNOWLEDGMENTS}

The first author is thankful for the Department of Energy (DOE) Oak Ridge Institute for Science and Education (ORISE) for granting this life-changing EERE Robotics internship. He also thanks the host facility, Idaho National Laboratory (INL), and its staff for their priceless support to this work. We thank the anonymous reviewers at the Journal of Young Investigators (JYI) whose careful critiques and valuable comments helped improve and clarify this article. We also thank Heather Heidrich for her thorough editing of our revised manuscript to ensure the top copyediting.

\section{REFERENCES}

CAS DataBase List. (2016) Chemical Book, available: http://www.chemicalbook.com/CASDetailList_19500_EN.htm [accessed 25 Jul 2019].

Copley, J. R. D. and Udovic, T. J. (1993). Neutron time-of-flight spectroscopy. Journal of Research of the National Institute of Standards and Technology (NIST), 981, 71-87, available: http://dx.doi.org/10.6028/ jres.098.006

Cochrane (2020). Cochrane Collaboration Glossary, available: http://community.cochrane.org/glossary [accessed 26 May 2020].

Crawford, R. K. (2000). Neutron scattering instrumentation: A guide to future directions. 15th Meeting of the International Collaboration on Advanced Neutron Sources, Tsukuba, Japan, 06-09 Nov.

Department of Energy (2015a). Chapter 6: Innovating clean energy technologies in advanced manufacturing' in U.S. Department of Energy (DOE). Quadrennial Technology Review (QTR) 2015: An Assessment of Energy Technologies and Research Opportunities, available: http:// www.energy.gov/sites/prod/files/2017/03/f34/qtr-2015-chapter6.pdf [accessed 14 Jun 2019].

Department of Energy (2015b). Technology assessments for Chapter 6: 6A. Additive manufacturing' in U.S. Department of Energy (DOE). Quadrennial Technology Review (QTR) 2015: An Assessment of Energy Technologies and Research Opportunities, available: http://www.energy.gov/sites/prod/files/2015/11/f27/QTR2015-6A-Additive\%20Manufacturing.pdf [accessed 14 Jun 2019].

Department of Energy (2015c). Technology assessments for Chapter 6: 6C. Advanced sensors, controls, platforms and modeling for manufacturing (ASCPMM)' in U.S. Department of Energy (DOE). Quadrennial Technology Review (QTR) 2015: An Assessment of Energy Technologies and Research Opportunities, available: http://www.energy.gov/ sites/prod/files/2015/11/f27/QTR2015-6C-Advanced-Sensors-Controls-Platforms-and-Modeling-for-Manufacturing.pdf [accessed 21 Jun 2019].

Department of Energy (2015d). Technology assessments for Chapter 6: 6H. Materials for harsh service conditions' in U.S. Department of Energy (DOE), Quadrennial Technology Review (QTR) 2015: An Assessment of Energy Technologies and Research Opportunities, available: http:// www.energy.gov/sites/prod/files/2016/02/f29/QTR2015-6H-Materialsfor-Harsh-Service-Conditions.pdf [accessed 22 Jul 2019].

Department of Energy (2015e). Technology assessments for Chapter 6: 6J. Process intensification' in U.S. Department of Energy (DOE) Quadrennial Technology Review (QTR) 2015: An Assessment of Energy Technologies and Research Opportunities, available: http://www.energy.gov/sites/prod/files/2016/06/f32/QTR2015-6I-Process-Heating. pdf [accessed 12 Jul 2019].

Dunning, J. R., Pegram, G. B., Fink, G. A., Mitchell, D. P. and Segrè, E. (1935). Velocity of slow neutrons by mechanical velocity selector. Physical Review, 48(8), 704-704, available: http://dx.doi.org/10.1103/ PhysRev.48.704

Egelstaff, P. A. ed. (1965). Thermal neutron scattering. London and New York: Academic Press.

Ehlers, G., Podlesnyak, A. A., and Kolesnikov, A. I. (2016). The cold neutron chopper spectrometer at the Spallation Neutron Source: A review of the first 8 years of operation. Review of Scientific Instruments, 87(9), 1-34, available: http://dx.doi.org/10.1063/1.4962024.
Engineering ToolBox (2005). Refrigerants - Physical Properties, available: http://www.engineeringtoolbox.com/refrigerants-d_902.html [accessed $25 \mathrm{Jul} 2019]$.

Engineering ToolBox (2008). Thermal Conductivities for Some Common Liquids, available: http://www.engineeringtoolbox.com/thermal-conductivity-liquids-d 1260.html [accessed 25 Jul 2019].

Engineers Edge (2019). Thermal Conductivity of Liquids, available: http:// www.engineersedge.com/heat_transfer/thermal_conductivity_of_liquids_9921.htm [accessed $26 \mathrm{Jul}$ 2019].

Fermi, E., Marshall, J. and Marshall, L. (1947). A thermal neutron velocity selector and its application to the measurement of the cross section of Boron. Physical Review, 723, 193-196, available: http://dx.doi. org/10.1103/PhysRev.72.193.

Fermi, E. (1952). Fermi's Own Story. Chicago Sun-Times, 23 Nov 1952. Reprinted in The first reactor [40th anniversary commemorative edition], U.S. Department of Energy, 01 Dec 1982, 21-26, available: http://dx.doi.org/10.2172/782931.

Fultz, B., Herwig, K. W. and Long, G. G. (2010). Computational Scattering Science 2010: a report of a workshop funded by the National Science Foundation (NSF), available: http://www.its.caltech.edu/ matsci/Publish/CSS_2010.pdf [accessed 26 May 2020].

Fultz, B., Kelley, T., Lin, J., Lee, J. D., Delaire, O., Kresch, M., McKerns, M. and Smith, H. (2018). Experimental inelastic neutron scattering with a chopper spectrometer and virtual neutron scattering with a computer. New York: Springer-Verlag.

Glossary. (n.d.). Nuclear Power, available: http://www.nuclear-power.net/ glossary/ [accessed $26 \mathrm{Jul}$ 2019].

Harling, O. (1966). Phased rotating crystal and chopper for time-of-flight neutron spectroscopy. Review of Scientific Instruments, 376, 697-709, available: http://dx.doi.org/10.1063/1.1720299.

Lee, G. H., Chang, Y. and Kim, T.-J. (2014). 2 - Properties and Possible Application Areas' in Lee, G. H., Chang, Y. and Kim, T.-J., eds., Ultrasmall lanthanide oxide nanoparticles for biomedical imaging and therapy. Cambridge: Woodhead Publishing, 15-28.

Lowde, R. (1960). The principles of mechanical neutron-velocity selection. Journal of Nuclear Energy - Part A. Reactor Science, 112, 69-80, available: http://dx.doi.org/10.1016/0368-3265(60)90017-7.

Lu, R., Swetha, C., Du Frane, W., Landingham, R., Worsley, M. and Kuntz, J. (2018). Complex shaped Boron carbides from negative additive manufacturing. Materials \& Design, 148(15 June 2018), 8-16, available: http://dx.doi.org/10.1016/j.matdes.2018.03.026.

Mobley, C. M. (1966). The construction of a Fermi neutron chopper for cross section measurements, thesis (M.S.), University of Missouri at Rolla, available: http://scholarsmine.mst.edu/masters_theses/5788 [accessed 05 Jun 2019].

NIST Standard Reference Database Number 69. (2018). National Institute of Standards and Technology (NIST), available: http://webbook.nist. gov/chemistry/ [accessed 25 Jul 2019].

National Oceanic and Atmospheric Administration (1999). Database of hazardous materials. in U.S. National Oceanic and Atmospheric Administration (NOAA), available: http://cameochemicals.noaa.gov [accessed 01 Aug 2019].

Panchak, P. (2012). The manufacturer's agenda: why we need a better definition of "Advanced Manufacturing". Industry Week, available: http:// www.industryweek.com/leadership/article/21959102 [accessed 04 Aug 2020].

President's Council of Advisors on Science and Technology (2010). White papers on advanced manufacturing questions by President's Council of Advisors on Science and Technology (PCAST), Washington, DC available: http://www.nist.gov/system/files/documents/2017/05/09/ advanced-manuf-papers.pdf [accessed 14 Jun 2019]

President's Council of Advisors on Science and Technology (2012). Capturing domestic competitive advantage in advanced manufacturing by President's Council of Advisors on Science and Technology (PCAST), Washington, DC, available: http://www1.eere.energy.gov/manufacturing/pdfs/pcast_july2012.pdf [accessed 04 Aug 2020]. 


\section{$\stackrel{\bullet \bullet}{\ddots J Y I}$ Journal of Young Investigators}

Pesente, S., Lunardon, M., Nebbia, G. and Viesti, G. (2006). Detection of improvised explosives devices (IED) by using tagged neutron beams' in Schubert, H. and Kuznetsov, A., eds., Detection and disposal of improvised explosives. NATO security through science series - B: Physics and biophysics, Dordrecht: Springer, 69-85, available: http://dx.doi. org/10.1007/978-1-4020-4887-6_7.

Rachuri, S. (2017). Smart and advanced manufacturing innovation in DOE. presented at the College of Engineering at Carnegie Mellon University: Seminar by Program Officer and Technology Manager of Advanced Manufacturing Office (AMO), Office of Energy Efficiency and Renewable Energy (EERE), U.S. Department of Energy (DOE), $25 \mathrm{Apr}$, available: http://engineering.cmu.edu/news-events/events/2017/04/25smart-advanced-manufacturing.html [accessed 13 Jun 2019].

Right Price Chemicals. (n.d.). available: http://www.rightpricechemicals. com [accessed 01 Aug 2019].

Subcommittee for Advanced Manufacturing (2016). Advanced manufacturing: A snapshot of priority technology areas across the federal government by Subcommittee for Advanced Manufacturing (SAM) of the National Science and Technology Council (NSTC), Washington, DC, 06 Apr, available: http://www.manufacturingusa.com/reports/advancedmanufacturing-snapshot-priority-technology-areas-across-federalgovernment [accessed 14 Jun 2019].

Sher, D. (2019). Lung-inspired 3D printed heat exchanger could make carbon dioxide power plants a reality. 3D Printing Media Network, $03 \mathrm{Jul}$, available: http://www.3dprintingmedia.network/lung-inspired-3d-printed-heat-exchanger/ [accessed 08 Jul 2019].

Soldner, T. (2015). Neutron Optics. Fundamental Neutron Physics Summer School 2015, University of Tennessee, available: http://www.phys.utk. edu/neutron-summer-school/lectures/soldner-01.pdf [accessed $15 \mathrm{Jul}$ 2019].

Sutton, L. (2018). 1935-2015: 80 years of neutron choppers. European Spallation Source (ESS), available: http://europeanspallationsource. se/sites/default/files/files/document/2018-08/A\%20need\%20for\%20 speed $\% 21 \% 20 a \% 20$ chopper\%20retrospective $\% 204.5$ c.pdf [accessed 14 Jun 2019].

Windsor, C. G. (1981). Pulsed neutron scattering. London: Taylor and Francis.

Yaws, C. (1995). Handbook of thermal conductivity (Vol. 1), Houston, TX: Gulf Professional Publishing. 